\title{
Combined in vivo muscle mass, muscle protein synthesis and muscle protein breakdown measurement: a 'Combined Oral Stable Isotope Assessment of Muscle (COSIAM)' approach
}

\author{
Jessica Cegielski • Daniel J. Wilkinson • Matthew S. Brook • \\ Catherine Boereboom • Bethan E. Phillips · John F. R. Gladman • \\ Kenneth Smith • Philip J. Atherton
}

Received: 1 March 2021 / Accepted: 17 May 2021 / Published online: 27 May 2021

(C) The Author(s) 2021

\begin{abstract}
Optimising approaches for measuring skeletal muscle mass and turnover that are widely applicable, minimally invasive and cost effective is crucial in furthering research into sarcopenia and cachexia. Traditional approaches for measurement of muscle protein turnover require infusion of expensive, sterile, isotopically labelled tracers which limits the applicability of these approaches in certain populations (e.g. clinical, frail elderly). To concurrently quantify skeletal muscle mass and muscle protein turnover i.e. muscle protein synthesis (MPS) and muscle protein breakdown (MPB), in elderly human volunteers using stable-isotope labelled tracers i.e. Methyl- $\left[\mathrm{D}_{3}\right]$-creatine $\left(\mathrm{D}_{3}-\mathrm{Cr}\right)$, deuterium oxide $\left(\mathrm{D}_{2} \mathrm{O}\right)$, and Methyl- $\left[\mathrm{D}_{3}\right]-3$-methylhistidine $\left(\mathrm{D}_{3}-3 \mathrm{MH}\right)$, to measure muscle mass, MPS and MPB, respectively. We recruited 10 older males $(71 \pm 4$ y,
\end{abstract}

J. Cegielski · D. J. Wilkinson · M. S. Brook ·

C. Boereboom · B. E. Phillips · J. F. R. Gladman ·

K. Smith · P. J. Atherton $(\bowtie)$

MRC-Versus Arthritis Centre for Musculoskeletal Ageing Research and NIHR Nottingham BRC, Clinical, Metabolic and Molecular Physiology, School of Medicine, University of Nottingham, Royal Derby Hospital Centre, Uttoxeter Road, Derby DE22 3DT, UK

e-mail: philip.atherton@nottingham.ac.uk

C. Boereboom

Nottingham University Hospitals NHS Trust, Nottingham, UK
BMI: $25 \pm 4 \mathrm{~kg} \cdot \mathrm{m}^{2}$, mean $\pm \mathrm{SD}$ ) into a 4-day study, with DXA and consumption of $\mathrm{D}_{2} \mathrm{O}$ and $\mathrm{D}_{3}$-Cr tracers on day $1 . \mathrm{D}_{3}-3 \mathrm{MH}$ was consumed on day $3,24 \mathrm{~h}$ prior to returning to the lab. From urine, saliva and blood samples, and a single muscle biopsy (vastus lateralis), we determined muscle mass, MPS and MPB. $\mathrm{D}_{3}$-Cr derived muscle mass was positively correlated to appendicular fat-free mass (AFFM) estimated by DXA $(r=0.69, P=0.027)$. Rates of cumulative myofibrillar MPS over 3 days were $0.072 \% / \mathrm{h}$ (95\% CI, 0.064 to $0.081 \% / \mathrm{h}$ ). Whole-body MPB over $6 \mathrm{~h}$ was 0.052 (95\% CI, 0.038 to 0.067 ). These rates were similar to previous literature. We demonstrate the potential for $\mathrm{D}_{3}-\mathrm{Cr}$ to be used alongside $\mathrm{D}_{2} \mathrm{O}$ and $\mathrm{D}_{3}-3 \mathrm{MH}$ for concurrent measurement of muscle mass, MPS, and MPB using a minimally invasive design, applicable for clinical and frail populations.

Keywords Stable isotope tracer - Skeletal muscle · Protein synthesis

\section{Introduction}

Skeletal muscle is the largest organ of the body by mass, accounting for $30-50 \%$ of whole-body total protein turnover [1-3]. It contributes to approximately $60 \%$ of basal metabolic rate [4]. Loss of muscle mass and function (sarcopenia) is linked to ill-health and clinical outcomes in ageing, and conditions such as diabetes and cachexia [5, 6]. Skeletal 
muscle metabolism is responsive to anabolic interventions such as exercise, nutrition, and certain pharmaceuticals [7-9]. The three main, related, parameters of muscle metabolism are: muscle mass, muscle protein synthesis (MPS), and muscle protein breakdown (MPB). As such, measurement of all three aspects within a single protocol is desirable.

Muscle volume and, by inference, mass can be measured using DXA, MRI and CT [10]. These techniques are minimally invasive; however, access to them for use can often be limited as they are costly, not readily accessible, and some (i.e. DXA and CT) expose the participant to ionising radiation [11]. DXA is the most ubiquitously employed imaging approach in skeletal muscle research, although it is subject to overestimation of muscle mass [12, 13]. This issue has led to the recent re-emergence of the stable isotope labelled tracer creatine technique [12], using methyl- $\left[\mathrm{D}_{3}\right]$-creatine $\left(\mathrm{D}_{3}-\mathrm{Cr}\right)$ to quantify whole-body skeletal muscle mass, as a minimally invasive, inexpensive, and accurate alternative to the aforementioned imaging approaches. Following ingestion of a known dose of $\mathrm{D}_{3}-\mathrm{Cr}$, the amount retained in the body can be determined from the quantification of the amount of labelled creatine that 'spills over' in a subsequent 24-h pooled urine sample. The ratio of labelled to unlabelled creatinine (which is derived from the conversion of creatine to creatinine in the total muscle pool [14]) in urine samples taken at 48 and $72 \mathrm{~h}$ after ingestion of $\mathrm{D}_{3}-\mathrm{Cr}$ is then determined, and from these measurements, the size of the whole body muscle creatine pool can be estimated [15]. A further simple calculation can then estimate total whole-body skeletal muscle mass, assuming that there is $4.3 \mathrm{~g}$ creatine per $\mathrm{kg}$ of muscle [12]. Using this approach, Clark et al. (2014) established a strong correlation $(\mathrm{r}=0.868)$ with whole-body muscle mass assessement using MRI.

MPS in vivo has traditionally been quantified using measures of uptake of stable isotopically labelled amino acids administered as an intravenous bolus or infusion [16-18], and this approach has been used experimentally to compare a baseline state (such as resting or fasted) with that after an intervention (e.g. feeding, exercise or a pharmacological agent) [9, 19, 20]. However, the quantification of 'free-living', cumulative MPS using non-substrate specific deuterium $\left(\mathrm{D}_{2} \mathrm{O}\right)$ tracing methods has recently emerged as an important advancement in the field. In these methods, deuterium is rapidly equilibrated in the body water pool (over 1-2 h), exchanges onto amino acids (such as alanine) through intermediary metabolic pathways and is subsequently incorporated into protein [21]. Measurement of these processes permits the quantitation of cumulative MPS over varying time periods from hours or days [22] to weeks or months $[9,19]$. As such, these approaches can be applied in free-living people outside of a laboratory, which facilitates their use in the study of, for example, nutrition and physical (in)activity/exercise over clinically meaningful time periods.

The quantification of MPB is arguably more difficult than both muscle mass and MPS. Traditional in vivo approaches include arterio-venous (A-V) balance and fractional breakdown methods [23, 24], quantifying the dilution of amino acid tracers across the A-V system of an isolated organ or limb following the breakdown of tissue protein. These invasive approaches are reliant upon robust and regular blood sampling and/or blood flow measures, both of which have inherent limitations, such as the practicality of numerous and correctly timed blood samples [25]. Another approach has been to measure the concentration of 3-methylhistidine (3-MH) in urine. 3-MH is a post-translational modification of contractile protein histidine residues, which are not subject to reincorporation into nascent peptide synthesis, as there is no aminoacyl-tRNA for 3-MH [26]. However, this approach lost favour as urinary 3-MH levels may be perturbed by dietary meat intake [27] (an alternative source of 3-MH); and the assumption that methylated-histidine is exclusively derived from skeletal muscle of the appendicular skeleton may be incorrect, as the gut has also been shown to be a source of 3-MH [28]. Nevertheless, an adaptation of this approach using tracer dilution was reported recently in which $10 \mathrm{mg}$ of stable isotopically labelled 3-methylhistidine (either $\mathrm{D}_{3}$ or ${ }^{13} \mathrm{C}$ ) was administerd orally, and the rate of dilution of this tracer by endogenously released 3-MH was determined in plasma or urine over $6 \mathrm{~h}$ to assess the rate of whole-body myofibrillar protein breakdown [26]. This method offers a simple, attractive alternative which does not require accurate and complete 24 -h urinary collection because a much more easily collected series of spot urine or plasma samples can be used.

To date, there has been no attempt to create a single protocol to streamline minimally invasive 
techniques to simultaneously measure muscle protein turnover and muscle mass. Being able to do so would have considerable clinical research application in non-laboratory settings (i.e. in the community, hospitals or care homes) and/or in patient groups who find it difficult to comply with, or understand, invasive approaches, such as frail individuals or those with disabilities. Therefore, the aim of this study was to develop a single combined oral stable isotope assessment of muscle (which we term 'COSIAM') to concurrently quantify skeletal muscle mass and muscle protein turnover; MPS and MPB, using stable isotope methods with $\mathrm{D}_{3}-\mathrm{Cr}, \mathrm{D}_{2} \mathrm{O}$ and $\mathrm{D}_{3}-3 \mathrm{MH}$, respectively.

\section{Methods}

\section{Study protocol}

This study was approved by The University of Nottingham Ethics Committee (A08122015) and conformed to the standards set by The Declaration of Helsinki (2013).

Ten healthy older males were recruited $(71 \pm 4 \mathrm{y}$, BMI: $25 \pm 4 \mathrm{kgm}^{2}$, mean $\left.\pm \mathrm{SD}\right)$. Before being enrolled into the study, all participants had a full medical screening. Height, weight, full medical history, blood pressure, an ECG and clinical chemistry (full blood count, urea and electrolytes, liver function tests, thyroid function tests and coagulation) were used to assess subject eligibility to participate in the study. Participants were excluded if they had a $\mathrm{BMI}>35 \mathrm{~kg} \cdot \mathrm{m}^{2}$, active cardiovascular disease, cerebrovascular disease, respiratory disease, metabolic disease, inflammatory bowel or renal disease, active malignancy, any musculoskeletal or neurological disorders, any signs of clotting dysfunction, any recent steroid treatment (within 6 months), or if on hormone replacement therapy. All participants were informed of the purpose of the study and of all the risks and procedures involved, before providing their written, informed consent.

On the first study day (Day 1), participants were asked to attend the unit at 8:30 am for a whole-body DXA scan, having fasted overnight. They provided a baseline saliva sample (to identify baseline body water enrichment) and then performed the Short Physical Performance Battery Test (SPPBT). Leg extensor strength (single-leg 1RM and maximal voluntary contraction for leg extension) and handgrip strength (using Takei (T.K.K. 5401 GRIP-D) handgrip dynamometer) were also measured. A baseline $10 \mathrm{ml}$ blood sample was taken to measure background blood/plasma alanine labelling prior to $\mathrm{D}_{2} \mathrm{O}$ exposure. A baseline urine sample was collected to measure $\mathrm{D}_{3}$-creatinine enrichment. Participants were then given three $50 \mathrm{ml}$ aliquots of 70 atom percent $\mathrm{D}_{2} \mathrm{O}$ to drink, each taken 25 min apart to minimise the risk of side effects such as dizziness or nausea that are sometimes reported after $\mathrm{D}_{2} \mathrm{O}$ consumption due to disturbance of specific gravity within the vestibular fluid [29]. $30 \mathrm{mg} \mathrm{D}_{3}-\mathrm{Cr}$ was included in the final $50 \mathrm{ml}$ aliquot of $\mathrm{D}_{2} \mathrm{O}$.

Two hours after consumption of the final $\mathrm{D}_{2} \mathrm{O}$ aliquot, participants provided another saliva sample, to be used to determine the plateau $\mathrm{D}_{2} \mathrm{O}$ concentration in body water.

Prior to leaving the laboratory, participants were provided with a container to collect all urine for $24 \mathrm{~h}$, a tube for a spot urine sample at $48 \mathrm{~h}$ and three tubes for saliva samples at 12, 24 and $48 \mathrm{~h}$ after the final $\mathrm{D}_{2} \mathrm{O}$ aliquot was consumed. These samples were used to measure $\mathrm{D}_{3}$-creatine spillover, urinary $\mathrm{D}_{3}$-creatinine enrichment and the size of the creatine pool, respectively. Participants were also given $10 \mathrm{mg}$ of $\mathrm{D}_{3}-3 \mathrm{MH}$ dissolved in $50 \mathrm{~mL}$ of water to take home and store refrigerated. Participants were instructed to consume the $\mathrm{D}_{3}-3 \mathrm{MH}$ immediately after the 48-h samples were collected (Fig. 1). Please refer to Fig. 1 for an illustrative depiction of the COSIAM approach.

Participants returned to the laboratory $72 \mathrm{~h}$ after consumption of the final $\mathrm{D}_{2} \mathrm{O}$ aliquot given on the first study visit, again having fasted overnight. At this visit, hourly bloods were collected over $6 \mathrm{~h}$ (between 72 and $78 \mathrm{~h}$ after consumption of the final $\mathrm{D}_{2} \mathrm{O}$ aliquot), plus a further spot urine and saliva sample at $72 \mathrm{~h}$. A muscle biopsy from the $m$. vastus lateralis (VL) was also taken at this visit (at $72 \mathrm{~h}$ ) under local anaesthetic (1\% lidocaine). The Bard micro-needle biopsy technique $(50 \%$ length of VL, mid-belly) was used for the first 5 participants, with the conchotome approach [30] used subsequently to achieve a larger tissue yield for further analyses. Participants were not fasted throughout the blood sampling period, with a standardised light meal 


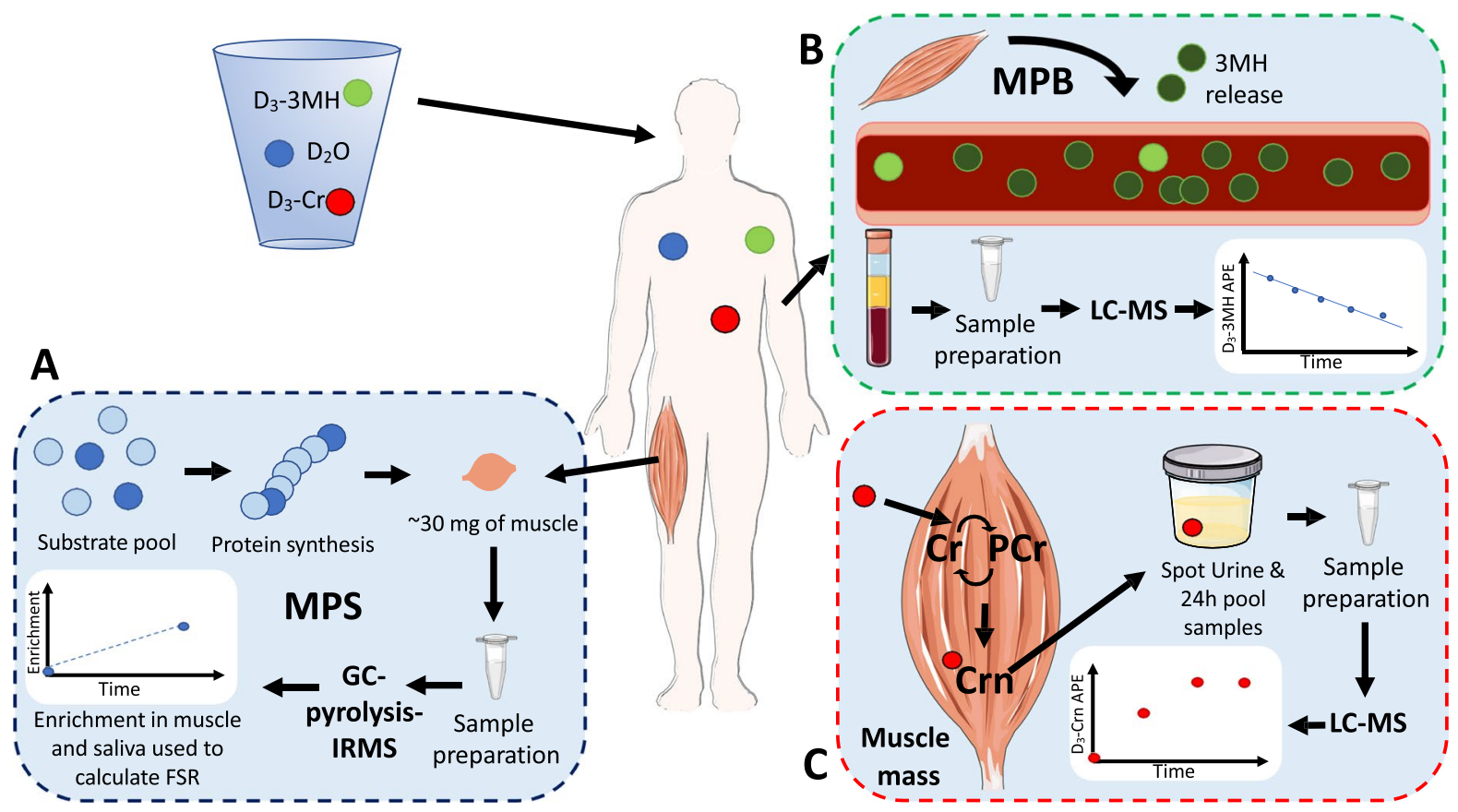

Fig. 1 Schematic representation of the combined use of $\mathrm{D}_{3}-3 \mathrm{MH}, \mathrm{D}_{2} \mathrm{O}$ and $\mathrm{D}_{3}-\mathrm{Cr}$ to measure myofibrillar muscle protein synthesis (MPS) (A), whole-body muscle protein breakdown (MPB) (B), and muscle mass (C), simultaneously

$150 \mathrm{~mL} \mathrm{D}_{2} \mathrm{O}$ and

$30 \mathrm{mg} \mathrm{D}_{3}$-Creatine

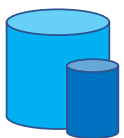

$10 \mathrm{mg} \mathrm{D}_{3}$-3-methylhistidine

Hour:

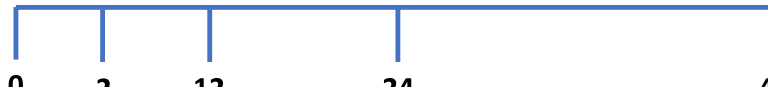
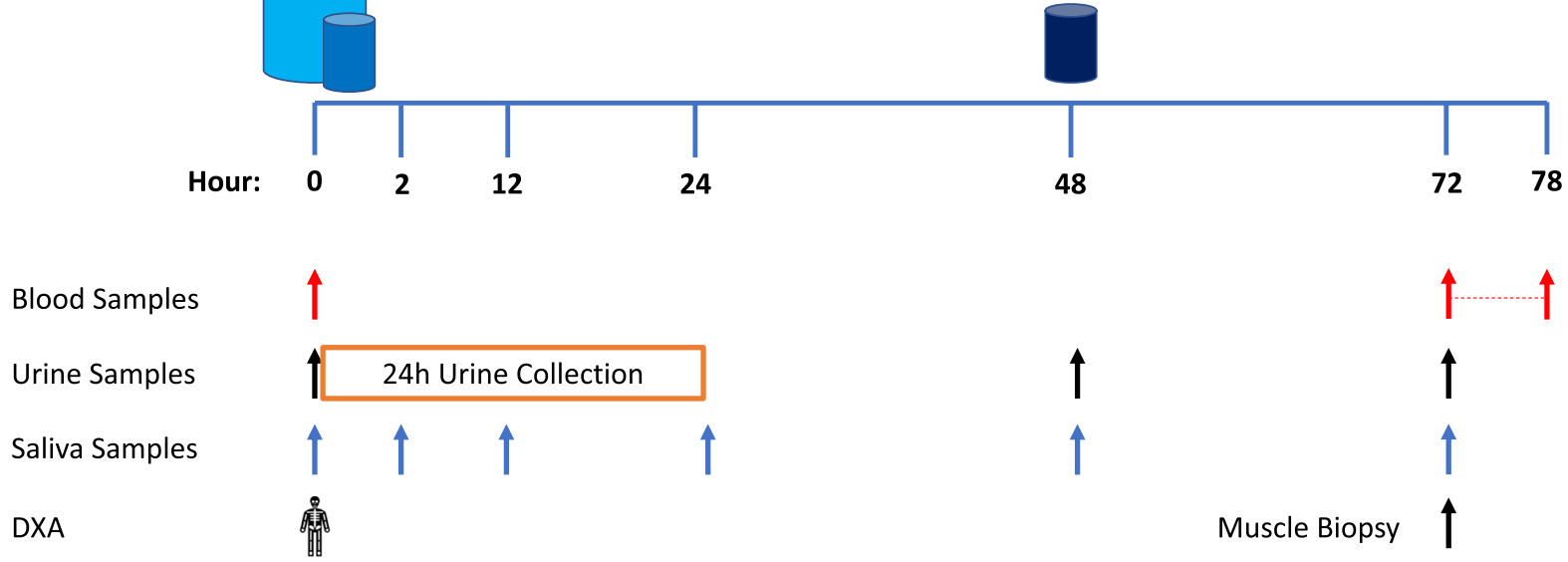

Muscle function assessment

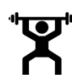

Fig. 2 Study schematic 
(sandwich, crisps, yoghurt and drink) provided at the midpoint of the blood collections for all participants. Figure 2 illustrates the protocol.

\section{Sample analysis}

\section{Measurement of body water enrichment in saliva, for the estimation of alanine precursor enrichment}

One hundred microlitres of each saliva was aliquoted into the cap of auto-sampler vials which were crimped onto inverted vials and placed on a heating block at $90{ }^{\circ} \mathrm{C}$ for $4 \mathrm{~h}$. These vials were then immediately cooled upright on ice for $10 \mathrm{~min}$ and the water collected transferred to fresh vials. The samples were then injected into a high temperature conversion elemental analyser (TC/EA; Thermo Scientific, Hemel Hempstead, UK) connected to an Isotope Ratio Mass Spectrometer (IRMS; Delta V Advantage, Thermo Scientific) [20]. The mean of the final 3 of 4 repeat injections was taken to control for carry over from previous samples. The mean area under the curve (AUC) of the atom percent excess (APE) was used to represent the average precursor labelling of free intramuscular alanine, multiplied by 3.7 to account for deuterium exchange into alanine from $\mathrm{D}_{2} \mathrm{O}$, for the determination of muscle fractional synthetic rate (FSR).

\section{Preparation of muscle for measurement of incorporation of deuterated alanine, for MPS determination}

Between 30 and $50 \mathrm{mg}$ of muscle was used for the analysis of deuterium labelling of alanine in the myofibrillar protein bound fraction, although $10 \mathrm{mg}$ is sufficient, thereby permitting the needle biopsy approach. The muscle tissue was homogenised with scissors in an Eppendorf tube using $10 \mu \mathrm{L} / \mathrm{mg}^{-1}$ of ice-cold homogenisation buffer $(50 \mathrm{mmol}$ Tris- $\mathrm{HCl}, 1 \mathrm{mmol}$ EDTA, 1 mmol EGTA, $10 \mathrm{mmol} \beta$-Glycerophosphate, $50 \mathrm{mmol} \mathrm{NaF}, 0.5 \mathrm{mmol}$ of activated sodium orthovanadate, pH 7.4 (all from Sigma Aldrich, Poole, UK) containing a complete protease inhibitor cocktail tablet (Roche, West Sussex, UK). The homogenate was mixed at $1000 \mathrm{rpm}$ for $10 \mathrm{~min}$ before being centrifuged at $10,000 \times \mathrm{g}$ for $10 \mathrm{~min}$ at $4{ }^{\circ} \mathrm{C}$. The supernatant (sarcoplasmic fraction) was then collected and the pellet was resuspended in $500 \mu \mathrm{L}$ mitochondrial extraction buffer (MEB) and then homogenized by Dounce and centrifuged at $1000 \mathrm{~g}$ for $5 \mathrm{~min}$. The myofibrillar pellet was solubilised using $1 \mathrm{~mL} 0.3 \mathrm{molL}^{-1} \mathrm{NaOH}$ and incubated for $30 \mathrm{~min}$ at $37{ }^{\circ} \mathrm{C}$, then centrifuged for $10 \mathrm{~min}$, at $4{ }^{\circ} \mathrm{C}$ and $10,000 \mathrm{rpm}$. The myofibrillar fraction (supernatant) was separated from the insoluble collagen pellet, and precipitated by the addition of $1 \mathrm{~mL} 1 \mathrm{molL}^{-1}$ perchloric acid, following incubation at $4{ }^{\circ} \mathrm{C}$ for $20 \mathrm{~min}$. The myofibrillar protein was pelleted at $4000 \mathrm{rpm}$ for $20 \mathrm{~min}$, separated from the supernatant containing the free amino acids, then washed twice with $70 \%$ ethanol. After the addition of $1 \mathrm{~mL} 0.1$ molL ${ }^{-1} \mathrm{HCl}$ and $1 \mathrm{~mL}$ of a Dowex $\mathrm{H}^{+}$resin slurry, the samples were incubated overnight at $110{ }^{\circ} \mathrm{C}$ in order to release the protein-bound amino acids [20, 31, 32]. The plasma was deproteinised using ice-cold ethanol (100\%) and centrifuged at $17,000 \mathrm{~g}$ for $10 \mathrm{~min}$. The pellet was transferred to a boiling tube containing on dowex with $0.1 \mathrm{M} \mathrm{HCl}$ and hydrolysed, overnight at $110{ }^{\circ} \mathrm{C} 16-20 \mathrm{~h}$; following the same preparation steps as the muscle sample.

The amino acids (AA) were derivatized as their $\mathrm{N}$-methoxycarbonyl methyl esters (MCME) as previously described [33]. Briefly, the AA were re-suspended in $60 \mu \mathrm{L}$ of distilled $\mathrm{H}_{2} \mathrm{O}$ and vortex mixed before the addition of $32 \mu \mathrm{L}$ of methanol and $10 \mu \mathrm{L}$ of pyridine. $8 \mu \mathrm{L}$ of methylchloroformate (MCF) was carefully added directly into the aqueous mix and immediately vortex mixed for $30 \mathrm{~s}$. The solution was left at room temperature for $5 \mathrm{~min}$ to react. Following the addition of $100 \mu \mathrm{L}$ of chloroform and $100 \mu \mathrm{L}$ of $0.001 \mathrm{M} \mathrm{NaHCO}_{3}$, the samples were vortexed mixed to extract the MCME amino acids. Molecular sieve was added to remove any excess water from the sample. The sample was transferred to an autosampler vial, ready for mass spectrometric analysis. Deuterium enrichment into protein-bound alanine was measured using gas-chromatography-pyrolysis-isotope-ratio-mass spectrometry (GC-pyrolysis-IRMS, Delta V Advantage, Thermo Scientific) [34].

The calculation of myofibrillar fractional synthetic rate was based on the following product-precursor equation:

$\operatorname{FSR}(\% / \mathrm{h})=-\operatorname{In}\left[\frac{1-\left(\frac{A P E_{A l a}}{A P E_{p}}\right)}{t}\right]$ 
where $\mathrm{APE}_{\mathrm{Ala}}$ is deuterium enrichment of proteinbound alanine, $\mathrm{APE}_{\mathrm{P}}$ is mean alanine enrichment corrected from $\mathrm{D}_{2} \mathrm{O}$, and $\mathrm{t}$ is the time between the plasma sample to the $72 \mathrm{~h}$ muscle biopsy, using previously described equations [19].

\section{Measurement of $D_{3}$-3-methyl-histidine in blood, for MPB determination}

Blood was taken, then centrifuged at $(3200 \mathrm{rpm}$, $20 \mathrm{~min}, 4{ }^{\circ} \mathrm{C}$ ), the plasma aliquoted into eppendorfs and stored at $-80^{\circ} \mathrm{C}$. Plasma samples were defrosted and centrifuged at $10,000 \mathrm{rpm}$ for $3 \mathrm{~min}$. A $0-10 \%$ $\mathrm{D}_{3}$-3-methyl-histidine enrichment curve was prepared as a serial dilution. $100 \mu \mathrm{L}$ of plasma was de-proteinised using $1 \mathrm{~mL}$ of $\mathrm{MeCN}$ : $\mathrm{MeOH}$ (1:1). Samples were vortex mixed and incubated at $-20{ }^{\circ} \mathrm{C}$ for $1 \mathrm{~h}$. Samples were centrifuged at $\sim 13,000 \mathrm{rpm}$ for $5 \mathrm{~min}$ at $4{ }^{\circ} \mathrm{C}$. The supernatant was dried down in a Techne Block at $<40{ }^{\circ} \mathrm{C}$ using nitrogen gas. Samples were re-suspended using $100 \mu \mathrm{L} \mathrm{MeCN}$ : $\mathrm{ddH}_{2} \mathrm{O}$ (65:35) and ready to be analysed using High-Performance Liquid Chromatography (HPLC; Dionex Ultimate 3000, Thermo Scientific) mass spectrometry (MS; Q-Exactive, Thermo Scientific) with a Sequant ZICHILIC column $(150 \mathrm{~mm} \times 2.1 \times 5 \mathrm{um}$; Merck Millipore). The flow was set to $0.4 \mathrm{~mL} / \mathrm{min}$ with an initial buffer gradient of 95:5 (Buffer A:B); where Buffer A was $10 \mathrm{mM}$ ammonium formate (90:10 Acetonitrile: $\left.\mathrm{ddH}_{2} \mathrm{O}\right)$ with $0.1 \%$ Formic Acid and Buffer B was $10 \mathrm{mM}$ ammonium formate (50:50 Acetonitrile: $\mathrm{ddH}_{2} \mathrm{O}$ ) with $0.1 \%$ Formic acid. After a 2.5-min hold at 95:5 (A:B), the buffer gradient was ramped to $100 \%$ Buffer B over $15 \mathrm{~min}$ and held for $2.5 \mathrm{~min}$ before returning back to 95:5 (A:B) and re-equilibrated for $10 \mathrm{~min}$. Accurate mass single ion monitoring was performed for $\mathrm{M}^{+} \mathrm{H}$ (mass +hydrogen cation): $170.09230(3 \mathrm{MH})$ and $173.11131\left(\mathrm{D}_{3}-3 \mathrm{MH}\right)$ to determine enrichment of $\mathrm{D}_{3}-3 \mathrm{MH}$. The enrichment ratios were $\log$ transformed to determine the decay rates $(\mathrm{k})$, representative of the rate of whole-body MPB [26].

\section{Determination of creatine spillover and creatinine enrichment in urine samples for calculation of whole body muscle mass}

The urine samples were prepared using a method based on that described by Leonard et al. [35]. Samples were freeze-thawed $(1 \times)$ at room temperature and vortex mixed, before $10 \mu \mathrm{L}$ of ${ }^{13} \mathrm{C}$-Creatine $(20 \mu \mathrm{g} / \mathrm{mL})$ was added to $50 \mu \mathrm{L}$ of urine, as an internal standard. $250 \mu \mathrm{L}$ of ice-cold acetonitrile was added both samples and standards, vortex mixed and cooled on ice for $30 \mathrm{~min}$. Samples were then centrifuged at $17,000 \mathrm{~g}$ for $20 \mathrm{~min}$. The supernatant was filtered through a $0.2 \mu \mathrm{m}$ filter and transferred to vials ready for HPLC-MS analysis using the same instrumentation and column as above [35]. The flow was set to $0.2 \mathrm{~mL} / \mathrm{min}, 60: 40$ (Buffer A:B) isocratic flow; where Buffer A was $100 \%$ Acetonitrile and Buffer B Ammonium Acetate $\mathrm{pH}$ 5.8. A standard curve using ${ }^{12} \mathrm{C},{ }^{13} \mathrm{C}$ and $\mathrm{D}_{3}$-Creatine was prepared for the determination of creatine concentration and enrichment (monitoring $\mathrm{M}+\mathrm{H}:$ 132.07666, 133.08006 and 135.09549 respectively), with a $\mathrm{D}_{3}$-creatinine enrichment curve of $0-0.1 \%$ for determination of $\mathrm{D}_{3}-$ creatinine enrichment (monitoring $\mathrm{M}+\mathrm{H}$ : 114.06638 and 117.08515).
Fig. 3 A Deuterium enrichment of the body water, measured in APE from saliva samples at baseline, $2,12,24,48$ and $72 \mathrm{~h}$ postdeuterium oxide ingestion; (B) Myofibrillar fractional synthetic rates. $\mathrm{n}=10$ older males. Mean and 95\% CI presented
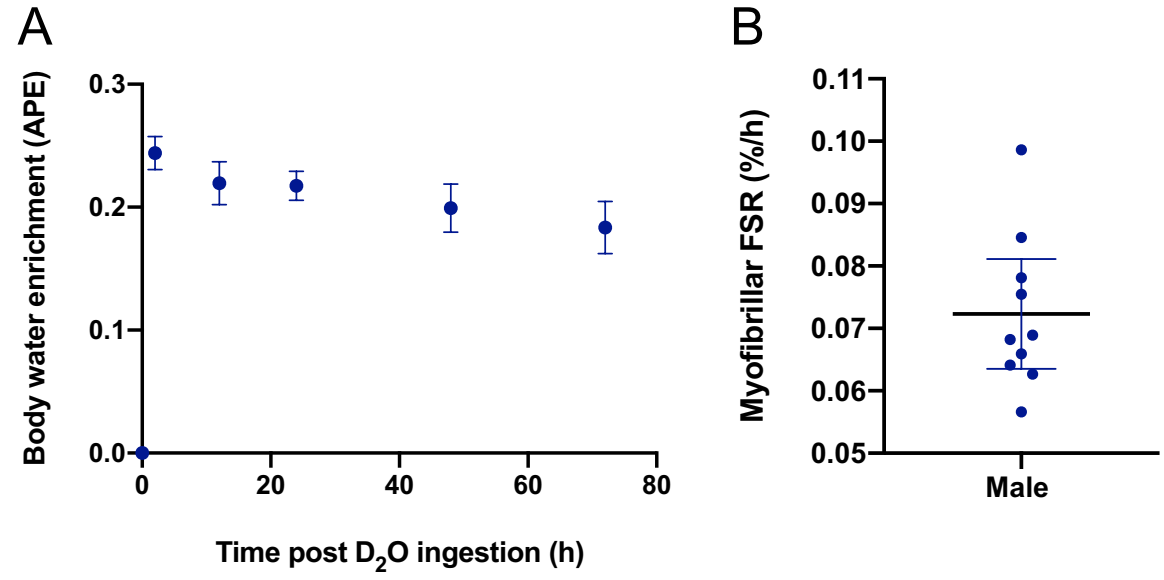
From the measurement of urinary $\mathrm{D}_{3}-$ creatine in the 24-h urine (spillover) and $\mathrm{D}_{3}-$ creatinine enrichment in the $48 \mathrm{~h}$ and $72 \mathrm{~h}$ spot urines, total creatine pool size and therefore total whole body muscle could be calculated using the following equation:
Determination of rates of muscle protein breakdown (MPB) by $D_{3}$-3-methylhistidine dilution

The $\mathrm{D}_{3}-3 \mathrm{MH}$ enrichment curve of $0-10$ APE (Fig. 4A) showed good linearity, whereby APE

Total muscle mass $=\frac{\left(\frac{M W_{\text {Unlabelled }}}{M W_{\text {labelled }}}\right) \times\left(\text { Amount of } D_{3}-C r \text { dosed }(g)-\text { Amount of } D_{3}-C r \text { excreted }(g)\right)}{\left(\text { mean steady }- \text { state } D_{3}-\text { Creatinine enrichment ratio }\right)} \div 4.3(\mathrm{~g} / \mathrm{kg})$

where $M W_{\text {Unlabelled }}$ and $M W_{\text {labelled }}$ represent the molecular weights of both unlabelled (131.1) and labelled creatine (134.1), respectively. The estimated creatine pool size is then divided by $4.3 \mathrm{~g} / \mathrm{kg}$ which reflects the average concentration of creatine found in whole wet muscle tissue [12].

\section{Statistical analyses}

As the methods have individually been previously validated, here we aimed to measure rates of MPS and MPB using our COSIAM approach, to identify if values obtained were similar to previous literature. Furthermore, we aimed to confirm if there was a relationship between DXA and $\mathrm{D}_{3}$-creatine-derived estimates of muscle mass. All data sets were tested for normality using Shapiro-Wilk test with alpha set at 0.05. Linear regression and two-tailed Pearson $r$ correlation analysis were used to identify any relationship between muscle mass estimates by $\mathrm{D}_{3}$-creatine and DXA, with confidence interval set at $95 \%$. All statistical analysis was performed using Graphpad Prism software (Prism 8, USA).

\section{Results}

Myofibrillar protein synthesis and body water enrichment

The mean body water enrichment of $\mathrm{D}_{2} \mathrm{O}$ peaked at $2 \mathrm{~h}$ (0.24 APE; 95\% CI, 0.23 to 0.26 APE) and then declined slowly over $72 \mathrm{~h}$ to $0.18 \mathrm{APE}$ (95\% CI, 0.16 to $0.20 \mathrm{APE}$; Fig. 3A). The mean myofibrillar FSR over $0-72 \mathrm{~h}$ was $0.072 \% / \mathrm{h}$ (95\% CI, 0.064 to $0.081 \% / \mathrm{h}$; Fig. 3B). measured at different enrichments were identical to the expected APE (slope=1.060). Mean plasma $\mathrm{D}_{3}-3-\mathrm{MH}$ enrichment gradually declined from $4.86 \pm 2.25 \mathrm{APE}$ at $24 \mathrm{~h}$ post-tracer ingestion to $3.65 \pm 1.82 \mathrm{APE}$ at $30 \mathrm{~h}$ (Fig. 4B). The ratio of labelled to unlabelled 3-MH was log transformed to determine the rate of whole-body MPB. The gradient of the straight line provides the $\mathrm{k}$ value (rate constant). The mean rate of whole-body MPB was 0.052 (95\% CI, 0.038 to 0.067 ; Fig. 4C).

\section{Determination of muscle mass using $D_{3}$-Creatine}

This analytical approach was extremely sensitive, accurate and robust, and both standard curves showed good linearity across both the range of concentrations of creatine expected (i.e. 0.25 to $5 \mu \mathrm{g}$; Fig. $5 \mathrm{~A}$ ) and expected $\mathrm{D}_{3}$-Cr enrichments (i.e. 0-0.1APE; Fig. 5B). In our hands, only very small amounts of $\mathrm{D}_{3}$-Cr were excreted during the $0-24 \mathrm{~h}$ collection period $(0.38 \%$ of the initial dose; Fig. 6B). $\mathrm{D}_{3}$-Cr enrichment in the urine samples increased over time and plateaued at $48 \mathrm{~h}$, there was no significant difference between 48 and $72 \mathrm{~h}$ enrichments (Fig. 6C); as such, the mean enrichment values of the $48 \mathrm{~h}$ and $72 \mathrm{~h}$ urine samples were then used to calculate muscle mass. There was no significant correlation between DXA-derived FFM and muscle mass measured by $\mathrm{D}_{3}-\mathrm{Cr}$ $(\mathrm{r}=0.55, \mathrm{p}=0.098)$. However, DXA-derived AFFM was significantly positively correlated with muscle mass measured by $\mathrm{D}_{3}-\mathrm{Cr}(\mathrm{r}=0.69, \mathrm{p}=0.027$; Fig. 6D).

\section{Discussion}

We present a minimally invasive study designed to measure rates of MPS, MPB and muscle mass concurrently, using a novel combination of orally ingested stable isotope labelled tracers, and mass 

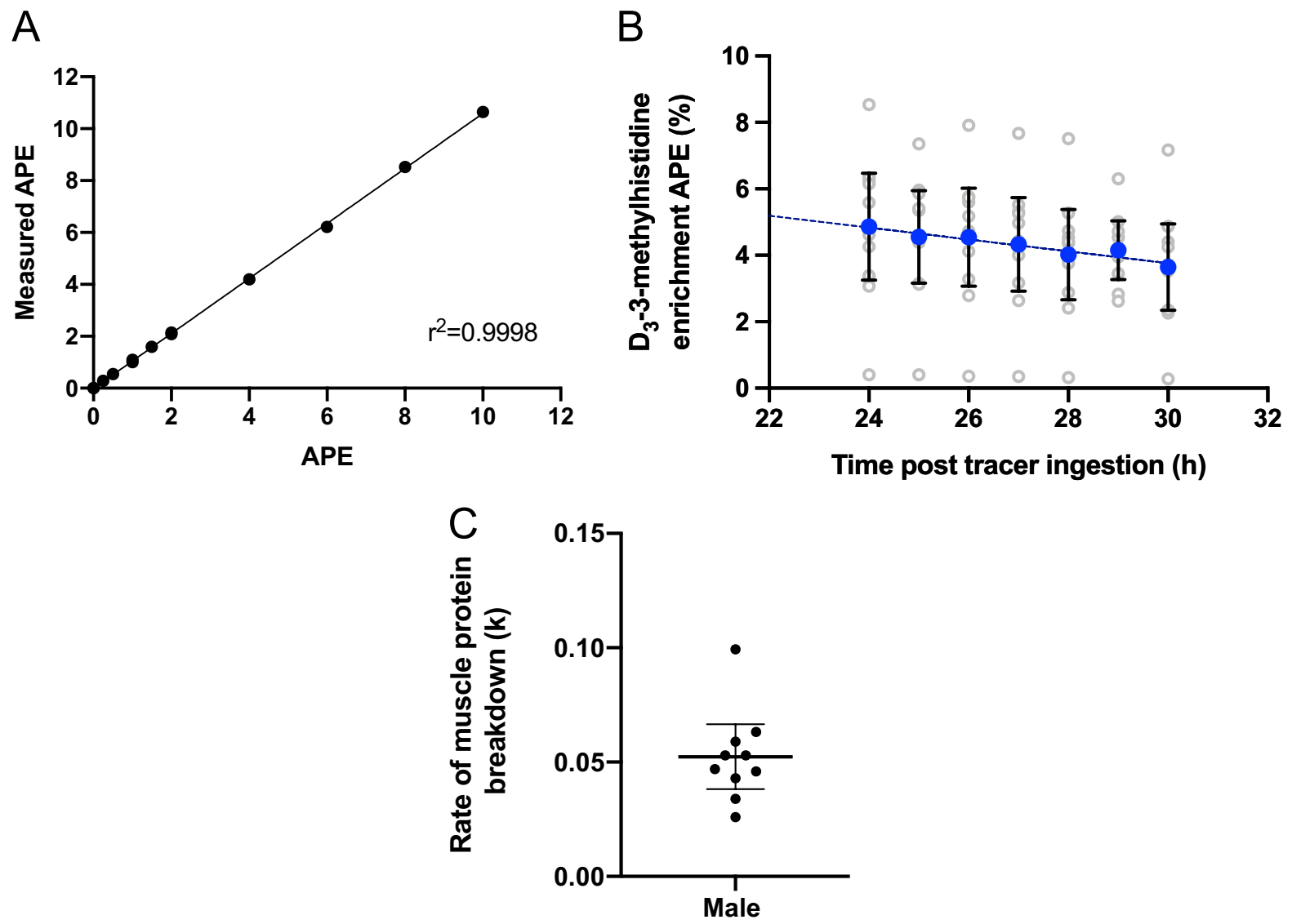

Fig. 4 A Enrichment curve of $D_{3}$-3-methylhistidine from 0-10 APE; (B) Decay curves of $\mathrm{D}_{3}$-3-methylhistidine in the plasma by endogenous 3-methylhistidine release; (C)
Rate of whole-body muscle protein breakdown (k) using $\mathrm{D}_{3}$-3-methylhistidine. $\mathrm{n}=10$ older males. Mean and 95\% CI presented
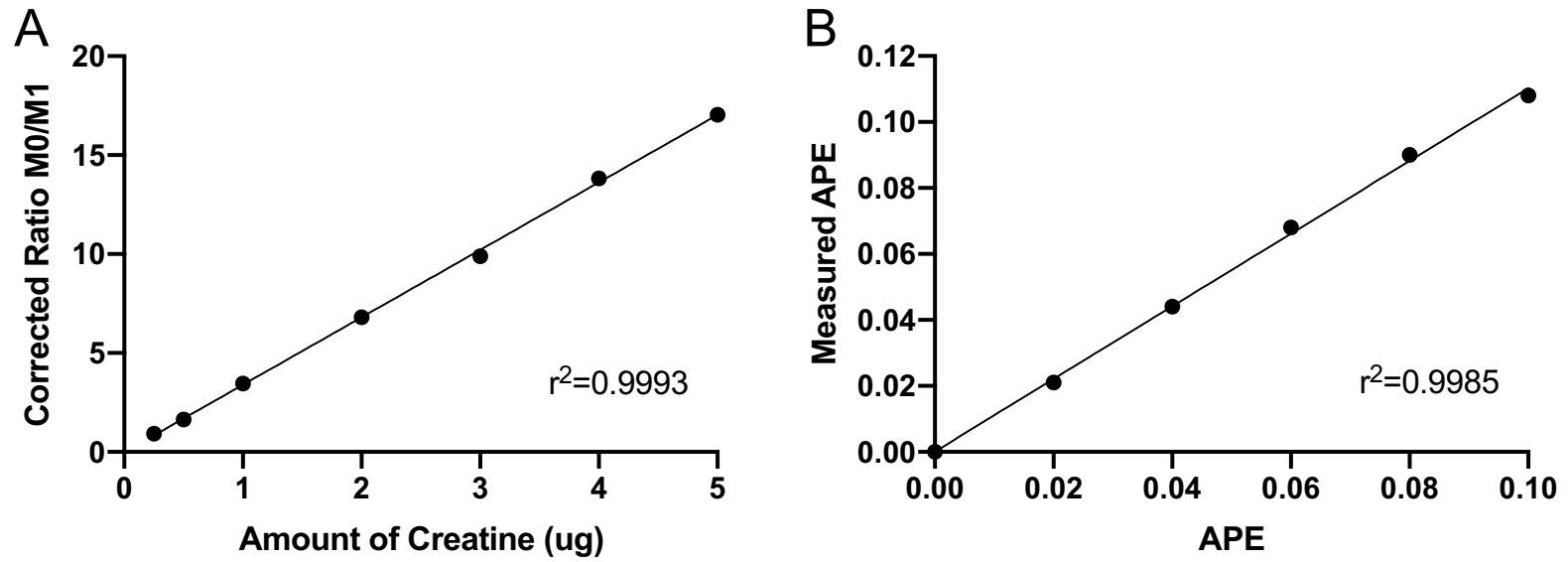

Fig. 5 A Creatine concentration curve ranging from $0.25-5 \mu \mathrm{g}$ of creatine where M0 is creatine and $\mathrm{M} 1$ is ${ }^{13} \mathrm{C}$-creatine; $(\mathbf{B})$ $\mathrm{D}_{3}$-creatinine enrichment curve ranging from 0 to 0.1 APE for measured vs. expected APE 
A

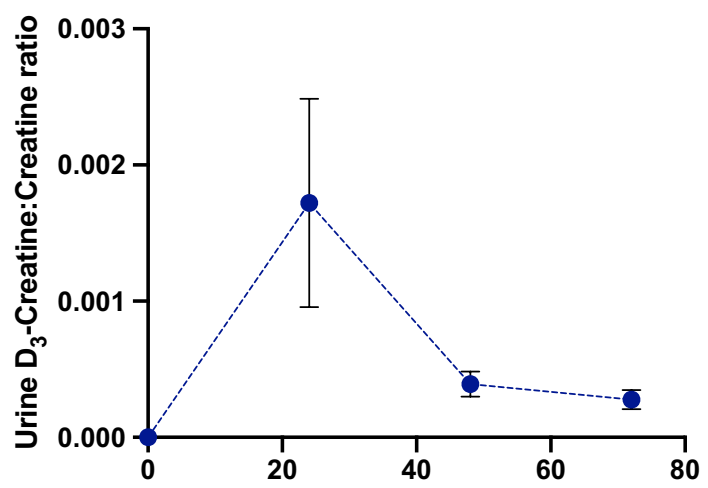

Time (h)

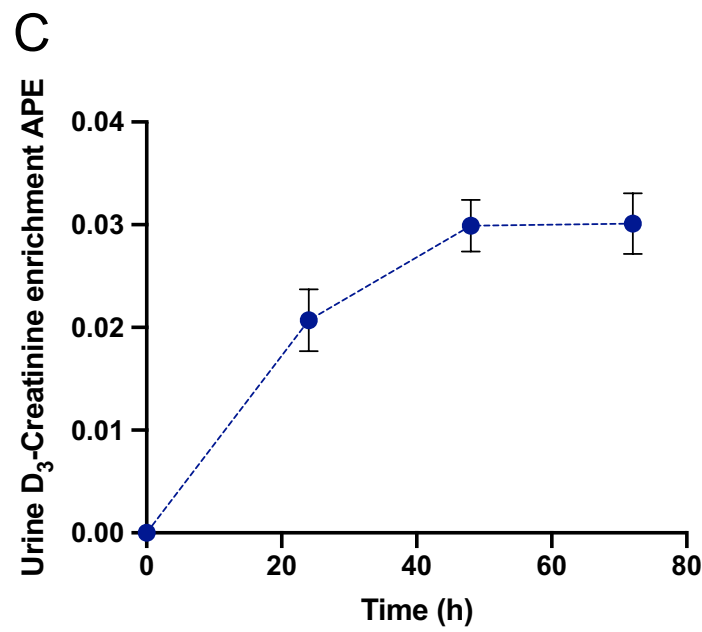

Fig. 6 A Corrected ratio of $\mathrm{D}_{3}$-Creatine/Creatine excreted in the urine for samples collected at Baseline $(0 \mathrm{~h}), 24 \mathrm{~h}$ (pool), 48 and $72 \mathrm{~h}$ (spot); (B) Percentage dose not absorbed by the body in $0-24 \mathrm{~h}$ urine collection sample. Values displayed are min to max; (C) Ratio of labelled creatinine $\left(\mathrm{D}_{3}\right.$-creatinine) to unlabelled creatinine, corrected to the baseline sample

spectrometric measures made in saliva, and blood or urine samples, in conjunction with a single muscle biopsy. In contrast to traditional stable isotope approaches using intravenous tracer infusions, which require extremely well-controlled laboratory conditions and imaging techniques, our protocol has the potential to be applied to a wider range of cohorts and settings.

In our protocol, we used a creatine tracer method to quantify muscle mass. The use of $30 \mathrm{mg} \mathrm{D}_{3}-\mathrm{Cr}$ tracer was based upon the dosing validation by Clark and colleagues in 2014 where $30 \mathrm{mg}$ was
B
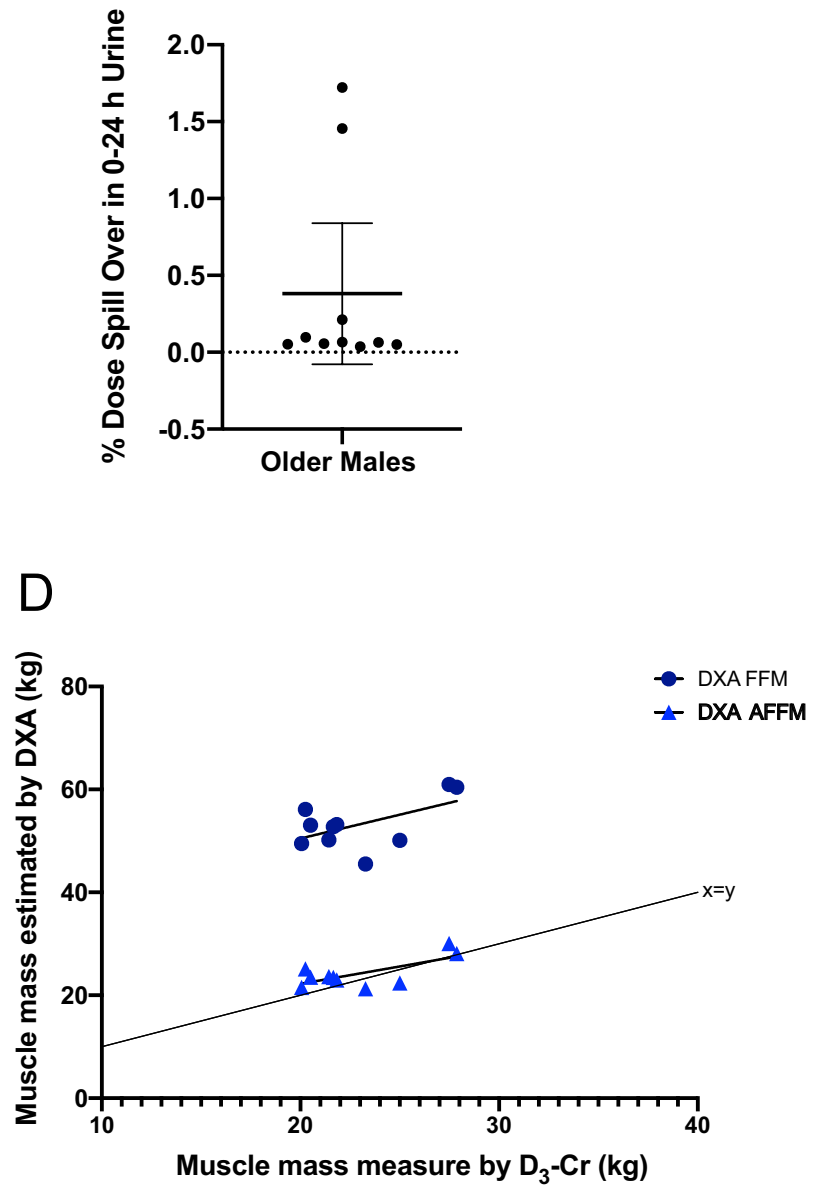

( $0 \mathrm{~h})$ for 24,48 and $72 \mathrm{~h}$ urine samples. Values displayed are mean $\pm 95 \%$ CI; (D) Correlation between muscle mass measured by $D_{3}$-Creatine method with fat free mass (FFM) and appendicular fat free mass (AFFM i.e. total arms and legs) measured by DXA. Values displayed are mean $\pm 95 \% \mathrm{CI}$

identified as adequate for quantification of muscle mass, a finding that we support. Our results also corroborate previous relationships between DXAderived parameters of skeletal muscle and muscle mass measured using $\mathrm{D}_{3}$-creatine $[12,36,37]$. A significant correlation was only found between muscle mass measured by $\mathrm{D}_{3}$-creatine and AFFM calculated from DXA (and not with FFM by DXA), this may be due to the fact that DXA does not measure muscle mass directly. Our findings are supported by those of Proctor et al., who found the strength of relationship between a urinary creatinine excretion 
method and DXA for assessing FFM declined with age [38]. In addition, FFM as measured by DXA is considerably higher $(\sim 60 \%)$ than the muscle mass determined using $\mathrm{D}_{3}$-creatine. Therefore, if DXA FFM is used to determine muscle mass, it will provide an erroneous overestimation of total muscle [and by extenstion, contractile] mass [39]. Ideally, the gold-standard approach to determine muscle mass (i.e., MRI) would have been used for comparison, however, a very close correlation between MRI and $\mathrm{D}_{3}$-creatine has been previously documented [12]. Although there is a strong correlation between AFFM using DXA or MRI, and muscle mass measured by $\mathrm{D}_{3}$-creatine, a potential limitation that requires further validation, is the widespread use of the $4.3 \mathrm{~g}$ creatine per $\mathrm{kg}$ muscle constant to calculate muscle mass based upon the size of the creatine pool [12]. It is important to ensure that the constant used accurately reflects intramuscular creatine in different populations, particularly where the muscle creatine pool size may vary e.g. vegetarians [40], athletes, especially following acute or endurance exercise [41] or when creatine is being supplemented in the diet [42]. When considering the impact of dietary intake, although a large amount of creatine can be found in meat, average ingestion is $\sim 1 \mathrm{~g} /$ day [43] in an omnivorous diet. In an average $70 \mathrm{~kg}$ young male the creatine pool size is approximately 120-140 g [43] with creatine excretion approximately $1.7 \%$ /day [44] as such average meat ingestion should not affect this measure; indeed significant changes in creatine pool size $(\sim 20 \%)$ have only been observed when supplementating creatine of $20 \mathrm{~g} /$ day over 6 days [45].

Given the precision of the $\mathrm{D}_{3}-\mathrm{Cr}$ measurement in our hands, we calculate it would be possible to detect a change in muscle mass of $1 \mathrm{~kg}$, equal to $\sim 0.03 \mathrm{APE}$, and therefore has the sensitivity to identify clinically meaningful changes [46]. Future applications of this approach could also look to minimise the urine sampling to a single spot urine, given that the spillover is less than $0.4 \%$ in our participants, perhaps due to the lower dose given, and this would lead to $<0.4 \%$ error in muscle mass calculation. We speculate that the percentage spillover may be related to the creatine pool size and thus, muscle mass and should be investigated further. Going forward, we suggest that 1 or 2 spot urine samples taken $48-72 \mathrm{~h}$ after ingestion of tracer would suffice, making the method even more practicable and widely applicable. To exemplify, in this data set, removing the correction of the $24 \mathrm{~h}$ collection, led to an average increase in muscle mass estimation of $9 \mathrm{~g}$. Alternatively, Shankaran et al. (2018), developed an algorithm to correct for $\mathrm{D}_{3}-\mathrm{Cr}$ spillage based on a relationship identified between fasting creatine:creatinine ratio and $\mathrm{D}_{3}-\mathrm{Cr}$ dose excreted from a urine sample, thereby, removing the need for the $24 \mathrm{~h}$ pooled collection [47].

Using $\mathrm{D}_{2} \mathrm{O}$ to study skeletal muscle protein metabolism is now a well-established stable-isotope tracer technique that has been validated for both longer (over weeks or months; [19]) and also relatively short study durations i.e. over 2-8 days [22], and even over as little as $3 \mathrm{~h}$ with appropriate increases in the preloading dose [20]. For instance, as little as $150 \mathrm{~mL}$ (70 AP) $\mathrm{D}_{2} \mathrm{O}$ ) was adequate to measure MPS over 2-8 days [22]; therefore, we used this dose to measure MPS in this 4-day protocol. In doing so, we report similar cumulative MPS values to those reported before [22, 48] and interference with the other coconsumed tracers $\mathrm{D}_{3}-\mathrm{Cr}$ or $\mathrm{D}_{3}-3 \mathrm{MH}$ (i.e. $\mathrm{D}_{2} \mathrm{O}$ contaminating creatine/methylhistidine labelling) is negligble. It is unlikely that a deuterium labelling of either arginine or glycine (amino acids involved in the initial step of creatine biosynthesis) from $\mathrm{D}_{2} \mathrm{O}$ would be incorporated to any extent into $\mathrm{D}_{3}$-labelled guanidinoacetate (a precursor to creatine), given the very small dose of $\mathrm{D}_{2} \mathrm{O}$ we use in this study, and therefore the probability of $\mathrm{D}_{2} \mathrm{O}$ labelling all three position of the methyl group at this level of dosing is vanishingly small. In addition, it is possible to provide an alternatively labelled tracer such as ${ }^{13} \mathrm{C}-\mathrm{Cr}$ for repeat measurements, and this would be recommended in short duration longitudinal studies to avoid any overlap of isotopes given the slow turnover of these pools [22].

For measurement of whole-body MPB, $10 \mathrm{mg}$ of $\mathrm{D}_{3}-3 \mathrm{MH}$ was utilised, as previously described by Sheffield-Moore and colleagues, with the rates of MPB in our older men similar to those previously observed (i.e. the rate constant $(\mathrm{k})$ of approximately 0.08, [26]). Sheffield-Moore et al. (2014), reported no significant difference between the use of meat or meatless diets in their study and therefore diet was not controlled for in our study. It is important to note that subjects were not maintained fasted throughout the period of plasma sampling for $\mathrm{D}_{3}-3 \mathrm{MH}$ measures, therefore the rates of MPB we observed reflect the changes in MPB over the period of sampling. Feeding 
increases insulin secretion which is known to inhibit MPB [49]; therefore, it is likely that our measures will somewhat reflect MPB in the fed state, thereby explaining why our MPB rates are slightly lower than the cummulative rates of MPS obtained in this study. One subject had a much lower $\mathrm{D}_{3}-3 \mathrm{MH}$ enrichment than the other subjects, which is probably indicative that they did not ingest the full $10 \mathrm{mg}$ or perhaps took the dose much earlier than reported i.e. not the morning before; however, the decay rate determined was similar to that of our other participants, due to the high sensitivity and reproducibility of the LC-MS approach employed. Further investigations could look to reduce the dose of $\mathrm{D}_{3}-3 \mathrm{MH}$ given or standardise the dose on a weight or LBM basis to standardise the approach and measurement of enrichment across participants. Furthermore, using timed urine samples, instead of blood samples for the measurement of labelled $\mathrm{D}_{3}-3 \mathrm{MH}$ excretion could further minimise the invasiveness of this approach [26].

Other considerations to the work presented herein are warranted. With regard to selecting which timepoint to take the spot samples, Clark et al. (2014) reported that a steady-state of $\mathrm{D}_{3}$-creatinine enrichment was achieved by $30.7 \pm 11.2 \mathrm{~h}$ post-tracer ingestion and remained steady for a further 5 days [12]. As such, a single spot urine sample taken at any timepoint during this steady-state period (2-4 days post-ingestion of tracer) would be sufficient. For more acute measures, the timepoint for MPS measurement could be altered i.e. shortened, and with an additional biopsy to measure MPS, with appropriate sampling over the same time frame (i.e. $6 \mathrm{~h}$ ) as MPB [20], also permitting us to adopt this approach pre- and post- longer term interventions. Although this would require additional biopsies, the use of the micro-needle biopsy technique [50], which is well tolerated [50], may be used towards developing a less invasive approach. It would also be possible to further shorten the time-frame and burden of these measures by providing all three tracers together on Day 0 , obtaining plasma/urine samples the next day for MPB and a muscle biopsy at $24 \mathrm{~h}$ for MPS, and a spot urine at $48 \mathrm{~h}$ or $72 \mathrm{~h}$ post-tracer consumption for muscle mass estimation. Additionally, future adaptations to the COSIAM approach may include the replacement of the muscle biopsy for the measurement of MPS with the use of the "virtual biopsy" approach to measure deuterium labelled plasma surrogates of MPS such as creatine kinase M-type (CK-M) or carbonic anhydrase 3 [51]. While this would further reduce the invasiveness of the approach and should be investigated further, the higher dose of deuterium oxide required for this approach may have a greater burden with the potential of increased side effects e.g. nausea. Furthermore, the relationship of plasma surrogates such as CK-M would require validation across different populations and scenarios. Finally, we speculate that where there is rapid muscle catabolism, such as in sepsis/burns, this approach would be equally valid for quantifying such gross perturbations in proteostasis (in fact one may speculate larger effect sizes would be easier to detect). Nonetheless, oral tracing of $\mathrm{D}_{3}-3 \mathrm{MH} / \mathrm{D}_{3}-\mathrm{Cr}$ does require gut/renal function and thus would need to be validated in relation to mapping the fate of oral tracers in populations of potential concern.

This study has demonstrated the feasibility of concurrent assessment of muscle protein turnover (i.e. MPS and MPB), and muscle mass through a far less invasive approach than using traditional stable isotope infusion approaches. The COSIAM approach provides rates of protein turnover and estimates of muscle mass that are in agreement with previous individual tracer approaches. The combination of these tracers via a minimally invasive approach has wider applicability than traditional methods and potential utility to provide novel, valuable information about the regulation of muscle mass in difficult to study clinical populations.

Acknowledgements The authors are grateful for the clinical support of Amanda Gates. This work and Jessica Cegielski were supported by a PhD studentship [RGS117347] from The Abbeyfield Research Foundation (charity number 1167685). This work was supported by the Medical Research Council [grant number MR/P021220/1] as part of the MRC-Versus Arthritis Centre for Musculoskeletal Ageing Research awarded to the Universities of Nottingham and Birmingham and the National Institute for Health Research (NIHR), Nottingham Biomedical Research Centre. The views expressed are those of the author(s) and not necessarily those of the Medical Research Council, NHS, the NIHR or the Department of Health and Social Care.

Open Access This article is licensed under a Creative Commons Attribution 4.0 International License, which permits use, sharing, adaptation, distribution and reproduction in any medium or format, as long as you give appropriate credit to the original author(s) and the source, provide a link to the Creative Commons licence, and indicate if changes were made. The images or other third party material in this article are included 
in the article's Creative Commons licence, unless indicated otherwise in a credit line to the material. If material is not included in the article's Creative Commons licence and your intended use is not permitted by statutory regulation or exceeds the permitted use, you will need to obtain permission directly from the copyright holder. To view a copy of this licence, visit http://creativecommons.org/licenses/by/4.0/.

\section{References}

1. Gasier HG, Fluckey JD, Previs SF. The application of $2 \mathrm{H} 2 \mathrm{O}$ to measure skeletal muscle protein synthesis. Nutr Metab (Lond). 2010;7:31.

2. Gasier HG, Riechman SE, Wiggs MP, Previs SF, Fluckey JD. A comparison of $2 \mathrm{H} 2 \mathrm{O}$ and phenylalanine flooding dose to investigate muscle protein synthesis with acute exercise in rats. Am J Physiol Endocrinol Metab. 2009;297(1):E252-9.

3. Frontera WR, Ochala J. Skeletal muscle: a brief review of structure and function. Calcif Tissue Int. 2015;96:183-95.

4. Johnstone AM, Murison SD, Duncan JS, Rance KA, Speakman JR. Factors influencing variation in basal metabolic rate include fat-free mass, fat mass, age, and circulating thyroxine but not sex, circulating leptin, or triiodothyronine. Am J Clin Nutr. 2005;82(5):941-8.

5. Morley JE, Malmstrom TK, Rodriguez-Mañas L, Sinclair AJ. Frailty, sarcopenia and diabetes. J Am Med Dir Assoc. 2014;15(12):853-9.

6. Rudrappa SS, Wilkinson DJ, Greenhaff PL, Smith K, Idris I, Atherton PJ. Human skeletal muscle disuse atrophy: effects on muscle protein synthesis, breakdown, and insulin resistance-a qualitative review. Front Physiol. 2016;7(August):1-10.

7. Cuthbertson DJ, Babraj J, Smith K, Wilkes E, Fedele MJ, Esser K, et al. Anabolic signaling and protein synthesis in human skeletal muscle after dynamic shortening or lengthening exercise. Am J Physiol Endocrinol Metab. 2006;290(4):E731-8.

8. Atherton PJ, Etheridge T, Watt PW, Wilkinson D, Selby A, Rankin D, et al. Muscle full effect after oral protein: time-dependent concordance and discordance between human muscle protein synthesis and mTORC1 signaling. Am J Clin Nutr. 2010;92(5):1080-8.

9. Gharahdaghi N, Rudrappa S, Brook MS, Idris I, Crossland $\mathrm{H}$, Hamrock C, et al. Testosterone therapy induces molecular programming augmenting physiological adaptations to resistance exercise in older men. J Cachexia Sarcopenia Muscle. 2019;1-19.

10. Heymsfield SB, Gonzalez MC, Lu J, Jia G, Zheng J. Skeletal muscle mass and quality: evolution of modern measurement concepts in the context of sarcopenia. Proc Nutr Soc. 2014;2015:1-12.

11. Kim J, Wang Z, Heymsfield SB, Baumgartner RN, Gallagher D. Total-body skeletal muscle mass: estimation by a new dual-energy X-ray absorptiometry method. Am J ClinNutr. 2002;76(0002-9165 (Print)):378-83.

12. Clark R V, Walker AC, O'Connor-Semmes RL, Leonard MS, Miller RR, Stimpson S a, et al. Total body skeletal muscle mass: estimation by creatine (methyl-d3) dilution in humans. J Appl Physiol. 2014;116(12):1605-13.

13. Levine JA, Abboud L, Barry M, Reed JE, Sheedy PF, Jensen MD, et al. Measuring leg muscle and fat mass in humans: comparison of CT and dual-energy X-ray absorptiometry. J Appl Physiol. 2000;88:452-6.

14. Wyss M, Kaddurah-Daouk R. Creatine and creatinine metabolism. Physiol Rev. 2000;80(3):1107-213.

15. Stimpson $\mathrm{S}$ a., Turner SM, Clifton LG, Poole JC, Mohammed $\mathrm{H}$ a., Shearer TW, et al. Total-body creatine pool size and skeletal muscle mass determination by creatine-(methyl-d3) dilution in rats. J Appl Physiol. 2012;112(17):1940-8.

16. Smith K, Reynolds N, Downie S, Patel a, Rennie MJ. Effects of flooding amino acids on incorporation of labeled amino acids into human muscle protein. Am J Physiol. 1998 Jul;275(1 Pt 1):E73-8.

17. Smith K, Barua JM, Watt PW, Scrimgeour CM, Rennie MJ. Flooding with L-[1-13C]leucine stimulates human muscle protein incorporation of continuously infused L-[1-13C]valine. Am J Physiol. 1992;262(3 Pt 1):E372-6.

18. Mitchell WK, Phillips BE, Williams JP, Rankin D, Lund JN, Smith K, et al. A dose- rather than delivery profile - dependent mechanism regulates the " muscle-full "” effect in response to oral essential amino acid intake. J Nutr. 2014;207-14.

19. Brook MS, Wilkinson DJ, Mitchell WK, Lund JN, Szewczyk NJ, Greenhaff PL, et al. Skeletal muscle hypertrophy adaptations predominate in the early stages of resistance exercise training, matching deuterium oxidederived measures of muscle protein synthesis and mechanistic target of rapamycin complex 1 signaling. FASEB J. 2015;29(11):4485-96.

20. Wilkinson DJ, Cegielski J, Phillips BE, Boereboom C, Lund JN, Atherton PJ, et al. Internal comparison between deuterium oxide (D 2 O) and L - [ring - 13 C 6 ] phenylalanine for acute measurement of muscle protein synthesis in humans. Physiol Rep. 2015;3(7):e12433.

21. Busch R, Kim Y-K, Neese RA, Schade-Serin V, Collins M, Awada M, et al. Measurement of protein turnover rates by heavy water labeling of nonessential amino acids. Biochim Biophys Acta. 2006;1760(5):730-44.

22. Wilkinson DJ, Franchi MV, Brook MS, Narici MV, Williams JP, Mitchell WK, et al. A validation of the application of D2O stable isotope tracer techniques for monitoring day-to-day changes in muscle protein subfraction synthesis in humans. Am J Physiol Endocrinol Metab. 2014;306(5):E571-9.

23. Volpi E, Sheffield-Moore M, Rasmussen BB, Wolfe RR. Basal muscle amino acid kinetics and protein synthesis in healthy young and older men. JAMA. 2001;286(10):1206-12.

24. Phillips SM, Tipton KD, Aarsland A, Wolf SE, Wolfe RR. Mixed muscle protein synthesis and breakdown after resistance exercise in humans. Am J Physiol. 1997;273:E99-107.

25. Katsanos CS, Chinkes DL, Sheffield-Moore M, Aarsland A, Kobayashi H, Wolfe RR. Method for the determination of the arteriovenous muscle protein balance during nonsteady-state blood and muscle amino acid concentrations. Am J Physiol - Endocrinol Metab. 2005;289(6):1064-70. 
26. Sheffield-Moore M, Dillon EL, Randolph KM, Casperson SL, White GR, Jennings K, et al. Isotopic decay of urinary or plasma 3-methylhistidine as a potential biomarker of pathologic skeletal muscle loss. J Cachexia Sarcopenia Muscle. 2014;5(1):19-25.

27. Huszar G, Golenwsky G, Maiocco J, Davis E. Urinary 3-methylhistidine excretion in man: the role of protein-bound and soluble 3-methylhistidine. Br J Nutr. 1983;49:287-94.

28. Sjölin J, Hjort G, Friman G, Hambraeus L. Urinary excretion of 1-methylhistidine: a qualitative indicator of exogenous 3-methylhistidine and intake of meats from various sources. Metabolism. 1987;36(12):1175-84.

29. Jones PJH, Leatherdale ST. Stable isotopes in clinical research: safety reaffirmed. Clin Sci. 1991;80:277-80.

30. Dietrichson P, Coakley J, Smith PEM, Griffiths RD, Helliwell TR, Tedwards RH. Conchotome and needle percutaneous biopsy of skeletal muscle. J Neurol Neurosurg Psychiatry. 1987;50(11):1461-7.

31. Kumar V, Atherton PJ, Selby A, Rankin D, Williams J, Smith K, et al. Muscle protein synthetic responses to exercise: effects of age, volume, and intensity. J Gerontol A Biol Sci Med Sci. 2012;67(11):1170-7.

32. Atherton PJ, Etheridge T, Watt PW, Wilkinson D, Selby A, Rankin D, et al. Muscle full effect after oral protein: time-dependent concordance and discordance between human muscle protein synthesis and mTORC1. Am J Clin Nutr. 2010;2:1080-8.

33. Hušek P. Chloroformates in gas chromatography as general purposederivatizing agents. J Chromatogr. 1998;717:57-91.

34. Brook MS, Wilkinson DJ, Mitchell WK, Lund JN, Phillips BE, Szewczyk NJ, et al. Synchronous deficits in cumulative muscle protein synthesis and ribosomal biogenesis underlie age-related anabolic resistance to exercise in humans. J Physiol. 2016;00:1-19.

35. Leonard M, Dunn J, Smith G. A clinical biomarker assay for the quantification of $\mathrm{d} 3$-creatinine and creatinine using LC-MS/MS. Bioanalysis. 2014;6(6):745-9.

36. Duchowny KA, Peters KE, Cummings SR, Orwoll ES, Hoffman AR, Ensrud KE, et al. Association of change in muscle mass assessed by D3-creatine dilution with changes in grip strength and walking speed. J Cachexia Sarcopenia Muscle. 2019;1-7.

37. Clark R V., Walker AC, Miller RR, O'Connor Semmes RL, Ravussin E, Cefalu WT. Creatine (methyl-d 3 ) dilution in urine for estimation of total body skeletal muscle mass-accuracy and variability vs. MRI and DXA. J Appl Physiol. 2018;124(1-9):jap.00455.2016.

38. Proctor DN, O'Brien PC, Atkinson EJ, Nair KS. Comparison of techniques to estimate total body skeletal muscle mass in people of different age groups. Am J Physiol Endocrinol Metab. 1999;277(3 40-3).

39. Evans WJ, Hellerstein M, Orwoll E, Cummings S, Cawthon PM. D3-Creatine dilution and the importance of accuracy in the assessment of skeletal muscle mass. $\mathbf{J}$ Cachexia Sarcopenia Muscle. 2019;10(1):14-21.

40. Blancquaert L, Baguet A, Bex T, Volkaert A, Everaert I, Delanghe $\mathrm{J}$, et al. Changing to a vegetarian diet reduces the body creatine pool in omnivorous women, but appears not to affect carnitine and carnosine homeostasis: a randomised trial. Br J Nutr. 2018;119(7):759-70.

41. Morris-Paterson TE, Barton ME, Someren KA Van, Leonard MS, Stimpson SA, Harridge SDR, et al. Total body skeletal muscle mass estimated by magnetic resonance imaging and creatine (methyl - $\mathrm{d} 3$ ) dilution in athletes. ScandJMedSciSports. 2019;(October):1-8.

42. Greenhaff PL, Bodin K, Soderlund K, Hultman E. Effect of oral creatine supplementation on skeletal muscle phosphocreatine resynthesis. Am J Physiol. 1994;266(5 Pt 1):E725-30.

43. Cooper R, Naclerio F, Allgrove J, Jimenez A. Creatine supplementation with specific view to exercise/sports performance: an update. J Int Soc Sports Nutr. 2012;9(1):1.

44. Stimpson SA, Leonard MS, Clifton LG, Poole JC, Turner SM, Shearer TW, et al. Longitudinal changes in total body creatine pool size and skeletal muscle mass using the D3-creatine dilution method. J Cachexia Sarcopenia Muscle. 2013;4(3):217-23.

45. Hultman E, Soderlund K, Timmons JA, Cederblad G, Greenhaff PL. Muscle creatine loading in men. J Appl Physiol. 2017;81(1):232-7.

46. Cruz P, Johnson BD, Karpinski SC, Limoges KA, Beth A, Olsen KD, et al. Validity of weight loss to estimate improvement in body composition in individuals attending a wellness center. Obes (Silver Spring). 2011;19(11):2274-9.

47. Shankaran M, Czerwieniec G, Fessler C, Wong P yin A, Killion S, Turner SM, et al. Dilution of oral D 3 -Creatine to measure creatine pool size and estimate skeletal muscle mass: development of a correction algorithm. J Cachexia Sarcopenia Muscle. 2018;9(3):540-6.

48. Murphy CH, Saddler NI, Devries MC, McGlory C, Baker SK, Phillips SM. Leucine supplementation enhances integrative myofibrillar protein synthesis in free-living older men consuming lower-and higher-protein diets: a parallel-group crossover study1. Am J Clin Nutr. 2016;104(6):1594-606.

49. Greenhaff PL, Karagounis LG, Peirce N, Simpson EJ, Hazell M, Layfield R, et al. Disassociation between the effects of amino acids and insulin on signaling, ubiquitin ligases, and protein turnover in human muscle. Am J Physiol Endocrinol Metab. 2008;295(3):E595-604.

50. Hayot M, Michaud A, Koechlin C, Caron MA, LeBlanc $\mathrm{P}$, Préfaut $\mathrm{C}$, et al. Skeletal muscle microbiopsy: a validation study of a minimally invasive technique. Eur Respir J. 2005;25(3):431-40.

51. Shankaran M, King CL, Angel TE, Holmes WE, Li KW, Colangelo $\mathrm{M}$, et al. Circulating protein synthesis rates reveal skeletal muscle proteome dynamics. J Clin Invest. 2016;126(1):288-302.

Publisher's note Springer Nature remains neutral with regard to jurisdictional claims in published maps and institutional affiliations. 